\title{
INDUKSI TEKNOLOGI MARKETING DIGITAL UNTUK MARKET EXPANTION DI KAMPUNG BATIK LAWEYAN SURAKARTA
}

\author{
Pipin Widyaningsih ${ }^{1}$, Faulinda Ely Nastiti ${ }^{2}$, Ety Meikhati ${ }^{3}$ \\ Program Studi Sistem Informasi STMIK Duta Bangsa Surakarta ${ }^{123}$ \\ E-mail : pipin_widyaningsih@stmikdb.ac.id ${ }^{1}$, faulinda_ely@stmikdb.ac.id ${ }^{2}$, \\ etymeikhati234@stmikdb.ac.id ${ }^{3}$
}

\begin{abstract}
Batik "Puspa Kencana" and Batik "Tahta" are part of batik industrial center located in Kampung Laweyan Surakarta. As a growing business unit in the global market, Batik "Puspa Kencana" and Batik "Tahta" have big challenges in market access and business competitiveness improvement. Marketing activities undertaken by both partners through the process of direct sales to customers and following the exhibition. The marketing model made the market access limited to Surakarta and its surrounding areas only. Utilizing technology by building online stores and digital profiles can be one solution to expand market access for Batik "Puspa Kencana" and Batik "Tahta" Laweyan. The methods used for community service activities are training, program implementation and application maintenance assistance. Partners are very enthusiastic and helped by the implementation of digital marketing because the introduction of stores and marketing activities can be done easily wherever and whenever through online stores and company digital profiles that can be accessed by internet and social media.
\end{abstract}




\begin{abstract}
ABSTRAK
Batik Puspa Kencana dan Batik Tahta laweyan merupakan bagian dari sentra industri batik yang berada di Kampung Laweyan kota Surakarta. Sebagai unit usaha yang berkembang di abad internet dan pasar global, Batik Puspa Kencana dan Batik tahta memiliki tantangan besar dalam hal akses pasar dan peningkatan daya saing usaha. Kegiatan pemasaran yang dilakukan oleh kedua mitra melalui proses penjualan langsung kepada pelanggan dan mengikuti pameran. Model pemasaran dan pengenalan toko yang dilakukan membuat akses pasar masih terbatas pada wilayah Surakarta dan sekitarnya saja. Pemanfaatan teknologi dengan membangun toko online dan profil digital dapat menjadi salah satu solusi untuk memperluas akses pasar bagi Batik Puspa Kencana dan Batik Tahta Laweyan. Metode yang digunakan untuk kegiatan pengabdian masyarakat adalah pelatihan, implementasi program dan pendampingan pemeliharaan aplikasi. Mitra sangat antusias dan terbantu dengan adanya implementasi pemasaran digital karena pengenalan toko dan kegiatan pemasaran dapat dilakukan dengan mudah dimanapun dan kapanpun melalui media toko online dan company profil digital yang dapat diakses melalui internet dan media sosial.
\end{abstract}

Kata Kunci: marketing digital, batik, market expantion 


\section{PENDAHULUAN}

Pengaruh internet dalam dunia bisnis membawa dampak yang sangat besar. Internet telah mengalami pergeseran fungsi dari alat pertukaran informasi elektronik menjadi menjadi strategi bisnis dalam bentuk aplikasi (penjualan, pelayanan pelanggan dan pemasaran) (Yuliana, 2000). Proses pemasaran melalui media internet dapat dilakukan setiap saat secara realtime tanpa terikat ruang dan waktu (Jinling, 2009). Kemudahan bertransaksi melalui media internet dan perubahan perilaku konsumen yang lebih menyukai bertransaksi secara online menjadi pemicu menjamurnya pemasaran online atau e-commerce. Pemanfaatan internet oleh pelaku usaha dapat menjadi salah satu strategi untuk menembus pasar yang lebih luas bahkan sangat mungkin menembus pasar global atau pasar ekspor. Adopsi pemasaran usaha secara digital atau online dapat menjadi salah satu faktor penting yang menentukan keberhasilan usaha (Prastuti, 2014).
Salah satu industri yang menjadi cirri khas Indonesia adalah industri Batik. Batik semakin mendunia setelah pengumuman UNESCO pada tanggal 2 Oktober 2009 yang menegaskan bahwa batik dijadikan salah satu warisan budaya Indonesia yang wajib dilindungi dan dilestarikan (Riani, 2014). Batik Indonesia dibuat dibanyak daerah di Indonesia yang menampilkan kekhasan masing-masing daerah. Meskipun banyak daerah memproduksi batik, namun perkembangan industri batik yang cukup pesat terletak di Pulau Jawa yaitu di daerah Indramayu, Cirebon, Pekalongan, Yogyakarta dan Solo.

Kota Solo (Surakarta) merupakan salah satu kota yang dikenal karena produksi batiknya. Batik yang terkenal dari Kota Solo adalah batik tulis (Sukma, 2014). Salah satu sentra kerajinan batik yang sangat terkenal adalah Kampung Laweyan. Kampung adalah salah satu sentra kerajinan batik yang letaknya tidak jauh dari Keraton Kasunanan Surakarta. Laweyan merupakan suatu kawasan unik, spesifik dan bersejarah. Laweyan telah dikenal sebagai sentra 
industri tenun dan batik sejak jaman kerajaan Pajang (Binarsih, 2013).

Adopsi strategi pemasaran digital ternyata memberikan beberapa keuntungan bagi unit usaha atau Usaha Mikro Kecil dan Menengah (UMKM) antara lain peningkatan kinerja Usaha Kecil Menengah (UKM) dengan adanya adopsi teknologi teknologi open source pada UKM (Fatmarini, 2011). Selain itu, adopsi e-commerce dapat memberikan pengaruh secara simultan terhadap volume penjualan sebesar 90,9\% (Sevtian, 2011). Penggunaa teknologi informasi pada UKM ternyata juga berpengaruh pada peningkatan pendapatan (Adi, 2008).

Batik Puspa Kencana dan Batik Tahta laweyan merupakan bagian dari sentra industri batik yang berada di Kampung Laweyan kota Surakarta. Sebagai unit usaha yang berkembang di abad internet dan pasar global, Batik Puspa Kencana dan Batik tahta memiliki tantangan besar dalam hal akses pasar dan peningkatan daya saing usaha. Berdasarkan hasil identifikasi masalah terdapat beberapa kendala yang dihadapi oleh mitra berdasarkan hasil pengamatan, pengisian angket, wawancara dan diskusi dengan mitra. Permasalahan yang dihadapi oleh mitra terkait dengan kegiatan pemasaran antara lain :

1. Toko memiliki jam operasi yang terbatas antara jam 09.00 sampai jam 16.00 dan tutup pada saat hari libur.

2. Promosi yang dilakukan saat ini berupa publikasi sederhana mengenai gerai batik di website Kampung Batik dan Facebook.

3. Pengenalan profil batik pada media internet seperti facebook atau blog hanya menampilkan gambar tanpa spesifikasi produk maupun link untuk memesan. Hal ini tentunya menyulitkan konsumen untuk mengetahui detail produk dan melakukan transaksi pembelian barang.

4. Meskipun kawasan kampung batik laweyan merupakan kawasan wisata belanja dan sejarah namun belum mampu meningkatkan 
pendapatan mitra secara signifikan.

5. Promosi dan pemasaran juga dilakukan dengan mengikuti pameran baik lokal maupun nasional namun tidak dilakukan secara intensif karena berdasarkan hasil wawancara proses promosi masih dilakukan dengan informasi dari orang ke orang (rekan kerja, tetangga atau relasi bisnis). Hasil wawancara terkait.

6. Proses pemasaran juga masih dilakukan secara simpel tanpa mengintergrasikan beberapa media (multimedia) seperti website, media sosial dan aplikasi smartphone.

7. Daerah pemasaran yang masih terbatas meliputi lokal dan sebagian kecil sudah menjangkau luar negeri (beberapa titik penjualan di Malaysia). Penjualan ke Malaysia menggunakan sarana komunkasi telepon dan email yang memiliki keterbatasan untuk mengenalkan produk batik dan transaksi.
8. Belum menerapkan strategi

pemasaran yang menjangkau wilayah pemasaran yang lebih luas dan belum ada kemudahan fasilitas untuk melakukan transaksi penjualan sehingga pemasaran dari bulan ke bulan cenderung konstan.

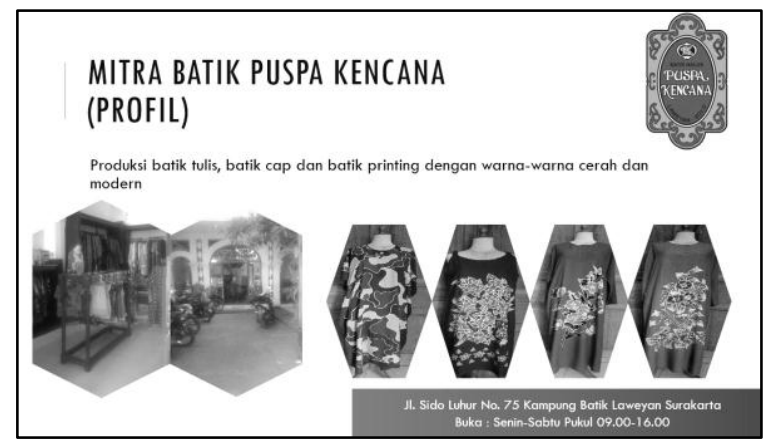

Gambar 1 Profil Mitra Batik Puspa Kencana

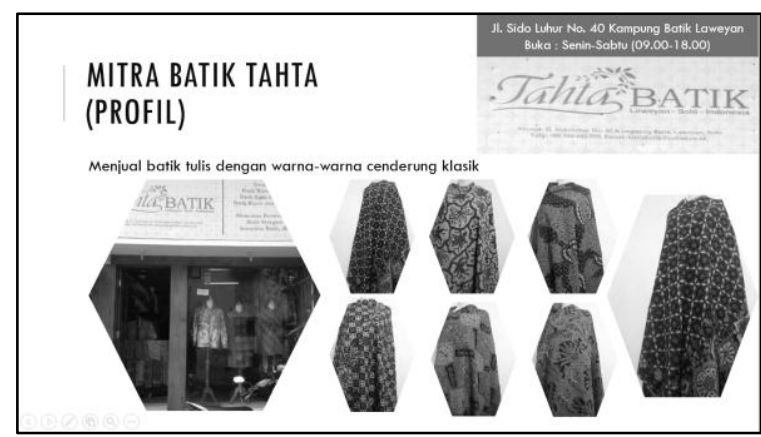

Gambar 2 Profil Mitra Batik Tahta

Solusi yang dirancang oleh tim pengusul telah melalui proses analisis dan diskusi dengan mitra. Berdasarkan hasil analisis dan diskusi dengan mitra mereka membutuhkan media untuk 
mengenalkan batik secara luas serta menekankan kepada konsep toko memperluas jaringan pemasaran. Hal online dan pembukuan usaha setelah ini berdasarkan kondisi yang dialami itu mitra diajak untuk mengetahui cara mitra karena keterbatasan yang dimiliki kerja toko online dan pembukuan usaha kampong batik terutama lahan parker melalui proses pelatihan. Pendekatan maka meskipun menjadi kawasan yang digunakan untuk proses wisata belanja, tingkat penjualan juga pendampingan adalah pendekatan tidak meningkat secara signifikan. Project Based. Mitra dan tim Adopsi teknologi pemasaran digital atau pengabdian terjun bersama-sama untuk e-commerce dapat menjadi salah satu membangun toko online, melakukan solusi untuk memperluas akses pasar bagi Batik Puspa Kencana dan Batik Tahta Laweyan. Selain itu pengenalan profil mitra melalui media sosial juga dapat dilakukan sebagai terobosan baru pengenalan mitra dengan jangkauan yang lebih luas.

\section{METODE}

update data, dan publikasi website. Pendekatan yang digunakan untuk kegiatan monitoring adalah problem solving. Tim pengabdian akan terus melakukan pendampingan, pemantauan dan evaluasi untuk membantu mitra mengatasi kendala yang terjadi pada proses implementasi program dan pemeliharaannya. Tahapan pelaksanaan kegiatan yang

Metode pelaksanaan kegiatan terdiri dilakukan antara lain : dari penyusunan materi, pelatihan, konfigurasi dan implementasi, pendampingan dan monitoring.

1. Penyusunan Materi

Pendekatan yang dilakukan untuk Modul pelatihan dibutuhkan agar pelatihan dapat berjalan lancar dan efisien. Modul pelatihan terdiri dari proses penyusunan materi dan pelatihan adalah pendekatan konsepmodul Instalasi, Konfigurasi dan Optimasilasi Toko Online proses. Pendekatan konsep proses 
2. Pelatihan

Untuk mengembangkan sistem pemasaran dan manajemen usaha serta meningkatkan ketrampilan para pengusaha batik maka akan dilakukan pelatihan pengembangan aplikasi toko online, pemeliharaan aplikasi toko online dan penyusunan company profil digital.

3. Konfigurasi dan Implementasi Program

Setelah melalui proses pelatihan maka tim pengusul bersama dengan mitra melakukan kegiatan persiapan peralatan dan konfigurasi sistem. Persiapan peralatan menyangkut perangkat keras (komputer, modem koneksi internet), perangkat lunak (browser). Konfigirasi sistem adalah proses instalasi dan setting aplikasi untuk persiapan implementasi program. Langkah selanjutnya adalah implementasi program adalah input data ke toko digital.
4. Pendampingan

Pendampingan dilakukan kepada mitra untuk melakukan pembelian dan pendaftaran domain dan hosting, menggunggah konten toko online ke halaman website dan melakukan pemutakhiran data secara online serta kegiatan launching website toko untuk mengenalkan toko kepada masyarakat. Tim pengabdian akan melakukan pemeliharan secara berkala dan berkelanjutan untuk mengatasi kesulitan yang dialami mitra.

5. Monitoring

Tim pengabdian akan memonitor tingkat pemutakhiran data yang dilakukan oleh mitra secara online. Tim pengabdian monitoring akan dilakukan secara berkala yaitu satu bulan sekali.

\section{HASIL, PEMBAHASAN DAN DAMPAK}

Tim pengabdian masyarakat melakukan koordinasi dengan mitra untuk membahasa roadmap kegiatan 
pengabdian masyarakat yang meliputi :

(1)Pembangunan Toko Online,

(2)Penyusunan Materi, (3)Pelatihan, (4)

Konfigurasi dan Implementasi,

(5)Pembuatan Company Profil Digital.

\section{Pembanguan Toko Online}

Survei yang dilakukan sepanjang 2016 itu menemukan bahwa 132,7 juta orang Indonesia telah terhubung ke internet. Adapun total penduduk Indonesia sendiri sebanyak 256,2 juta orang. Hal ini mengindikasikan kenaikan 51,8 persen dibandingkan jumlah pengguna internet pada 2014 lalu. Survei yang dilakukan APJII pada 2014 hanya ada 88 juta pengguna internet. "Penyebabnya adalah perkembangan infrastruktur dan mudahnya mendapatkan smartphone atau perangkat genggam," terang Ketua APJII Jamalul Izza saat ditemui Kompas Tekno di sela pengumuman Riset Pengguna Internet Indonesia 2016, di Jakarta, Senin (24/10/2016), Kompas (Pradiani, 2017).

Pesatnya penggunaan internet menjadi peluang bagi mitra pengabdian untuk memperluas akses pasar dengan membangun toko online. Toko online memiliki kelebihan dapat diakses oleh calon pelanggan tanpa terbatas tempat dan waktu. Hasil pembangunan toko online kedua mitra dapat dilihat pada gambar 3 dan gambar 4 .

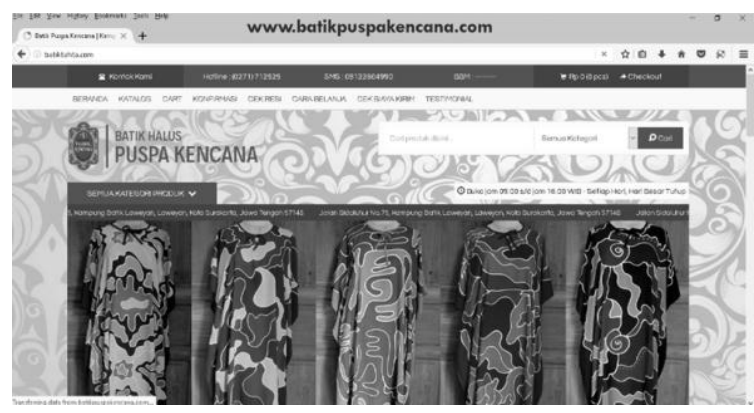

Gambar 3 Antarmuka Toko Online Batik Puspa Kencana

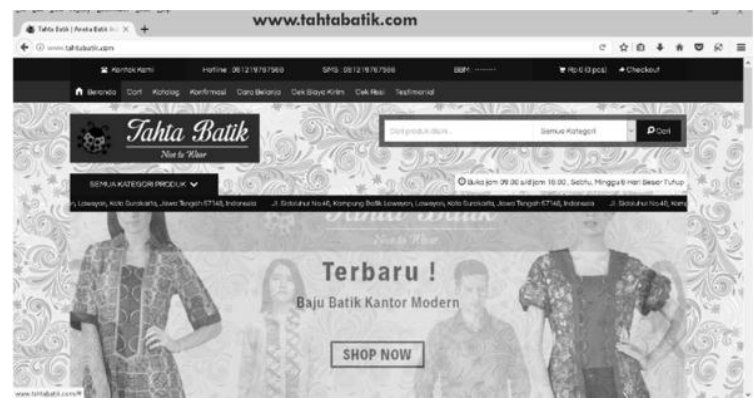

Gambar 4 Antarmuka Toko Online Batik

Tahta

\section{Penyusunan Materi Pelatihan}

Modul pelatihan dibutuhkan agar pelatihan dapat berjalan lancar dan 
efisien. Modul pelatihan terdiri dari modul Instalasi, Konfigurasi dan Optimasilasi Toko Online. Materi pelatihan meliputi memperbaru antarmuka toko, mengunggah produk, dan mengelola transaksi penjualan.
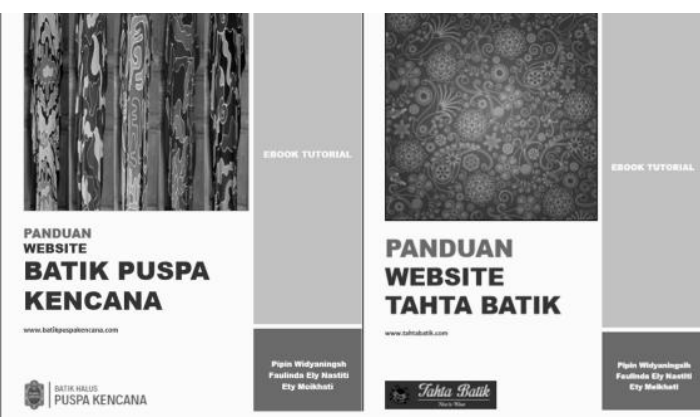

Gambar 5 Modul Pelatihan Toko Online

\section{Pelatihan}

Pelatihan diperlukan agar mitra dapat mengelola toko online yang sudah dibangun secara berkelanjutan. Kegiatan pelatihan disambut antusias oleh mitra. Pelatihan yang dilakukan meliputi memperbarui antarmuka toko, mengunggah produk, dan mengelola transaksi penjualan. Mitra juga tidak mengalami kendala berarti dalam mengikuiti pelatihan karena mitra sudah terbiasa mengoperasikan perangkat komputer. Kegiatan pelatihan bertujuan meningkatkan ketrampilan mitra dalam mengelola toko online.

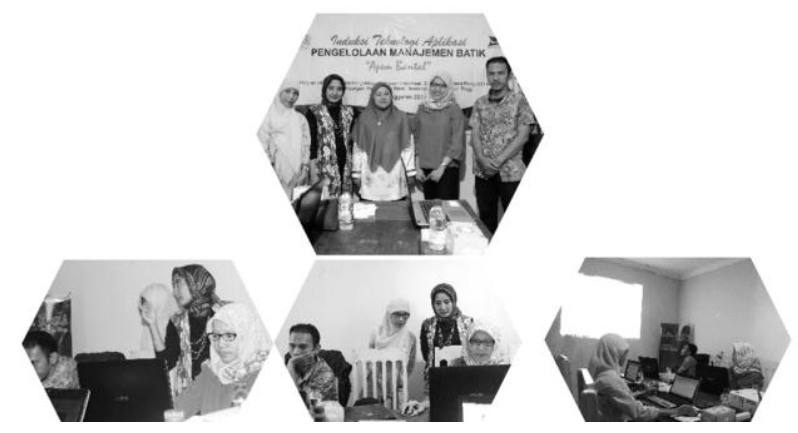

Gambar 6 Kegiatan Pelatihan

\section{Konfigurasi dan Implementasi}

Setelah melalui proses pelatihan maka tim pengusul bersama dengan mitra melakukan kegiatan persiapan peralatan dan konfigurasi sistem. Persiapan peralatan menyangkut perangkat keras (komputer, modem koneksi internet), perangkat lunak (browser). Konfigirasi sistem adalah proses instalasi dan setting aplikasi untuk persiapan implementasi program. Langkah selanjutnya adalah implementasi program adalah input data ke toko digital. Mitra mendapatkan perangkat pengelolaan 
aplikasi toko online agar dapat visualisasi yang hadir secara nyata memelihara toko online secara tanpa harus datang langsung ke lokasi. berkelanjutan.

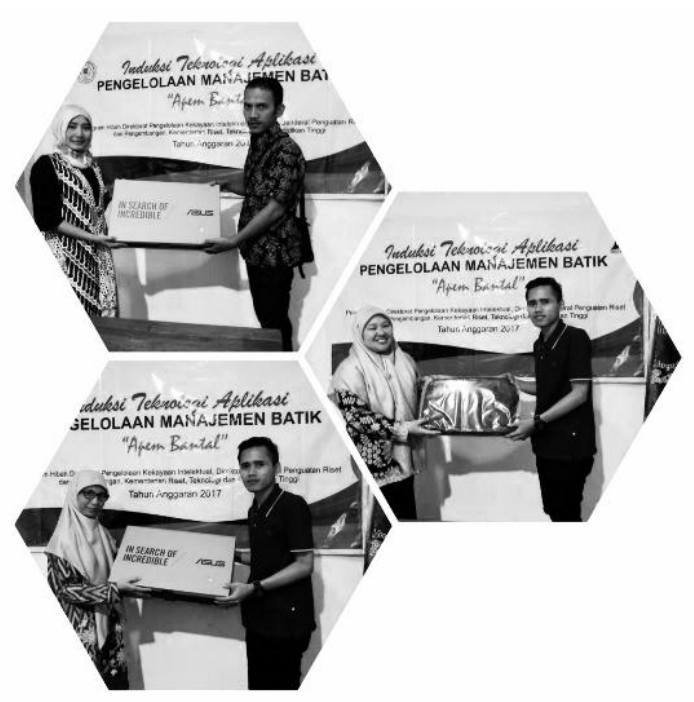

Gambar 7 Penyerahan Perangkat

Bantuan Pengelolaan Pemasaran Digital

\section{Pembuatan Company Profile Digital}

Company Profile adalah sarana untuk mengenalkan mitra kepada masyarakat secara umum. Pada era teknologi digital penyampaian company profile yang dapat diakses secara digital adalah pilihan tepat untuk menjangkau pasar yang lebih luas. Keuntungan profil digital adalah adanya dukungan

\section{Pendampingan dan Monitroring}

Pendampingan dilakukan kepada mitra untuk melakukan pembelian dan pendaftaran domain dan hosting, menggunggah konten toko online ke halaman website dan melakukan pemutakhiran data secara online serta kegiatan launching website toko untuk mengenalkan toko kepada masyarakat. Tim pengabdian akan melakukan pemeliharan secara berkala dan berkelanjutan untuk mengatasi kesulitan yang dialami mitra. Pendampingan implementasi toko online (pertemuan periodik untuk 
pengelolaan online) pada tahap awal 2 minggu sekali tahap selanjutnya 2 bulan sekali. Tim pengabdian akan memonitor tingkat pemutakhiran data yang dilakukan oleh mitra secara online. Tim pengabdian monitoring akan dilakukan secara berkala yaitu satu bulan sekali.

\section{PENUTUP}

Secara keseluruhan permasalahan pemasaran dan manajemen yang dihadapi oleh mitra dan perlu segera diselesaikan adalah :

a. Keterbatasan akses pasar karena jam operasi toko.

b. Keterbatasan sarana promosi

c. Keterbatasan wilayah pemasaran

d. Media pemasaran konvensional (mengandalkan informasi dari orang ke orang)

Kegiatan

Kegiatan yang telah dilakukan telah memberikan dampak terhadap terbukanya akses pasar yang lebih luas tanpa terkendala lokasi dan jam operasional toko. Kegiatan pendampingan sangat diperlukan agar mitra dapat mengelola toko online yang telah dibangun secara berkelanjutan. Komitmen dari tim pengabdian dan mitra sangat menentukan keberlanjutan aplikasi pemasaran digital.

\section{UCAPAN TERIMA KASIH}

Terima kasih kepada : (1) Direktorat Riset dan Pengabdian Masyarakat Direktorat Jenderal Penguatan Riset dan Pengembangan - Kementerian Riset, Teknologi, dan Pendidikan Tinggi Republik Indonesia, (2) LPPM STMIK Duta Bangsa Surakarta, (3) Batik Puspa Kencana Laweyan, (3) Batik Tahta Laweyan.

\section{REFERENSI}

Adi, B. 2008. Retrieved from Penerapan TI Memperkuat UKM India http://bambangriadi.com/br/200 8/10/penerapan-ti-memperkuatukm-india

Binarsih, Sri Rahayu dkk. 2013. Bisnis Internasional Bagi Pengusaha 
Kampung Batik Laweyan.

Prosiding Seminar Nasional Universitas Batik Surakarta : Menuju Masyarakat Madani dan Lestari. Hal. 101-110.

Fatmariani. 2011. Pengaruh Adopsi Teknologi Informasi Open Source E-commerce Terhadap Kinerja UKM dengan Faktor-Faktor Technology Acceptance Model (TAM) Sebagai Moderating Variabel. Jurnal Teknomatika Vol. 1 No. 1 Palembang STMIK PalComTech.

Jinling, C. e. 2009. Modeling Ecommerce Website Quality with Quality Function. IEEE International Conference on Deployment e-Business, 21-23.

Pradiani, Theresia. 2017. Pengaruh Pemasaran Sistem Pemasaran Digital Marketing Terhadap Peningkatan Volume Penjualan Hasil Industri Rumahan. Jurnal JIBEKA. Volume 11 Nomor 2. Hal. 46-53.

Prastuti Sulistyorini, Nur Ika Royanti, Era Yunianto. PENGARUH ADOPSI E-COMMERCE TERHADAP KEBERHASILAN USAHA (STUDI KASUS PEDAGANG BATIK DI PASAR GROSIR SETONO)Jurnal LITBANG Kota Pekalongan Tahun 2014

Riani S, Anastasia, Rahmawati, Seventi, Sri. 2014. Peningkatan Produktivitas Industri Batik di
Kampung Batik Laweyan

Surakarta. Prosiding Seminar Nasional Fakultas Ekonomi dan Bisnis Universitas Kristen Satya Wacana. Hal. 122-134.

Sevtian, F. I. 2011. Pengaruh Ecommerce Terhadap Tingkat Volume Penjualan Sandal Kelom Geulis Di CV Kelomgeulis Tasikmalaya. Skripsi . Jakarta: FPEB Universitas Pendidikan Indonesia.

Sukma, Ghosa Amorda. 2014. Analisis Pengendalian Kualitas Produk Batik Menggunakan Metode Fault Tree Analysis (FTA) dan Failure Mode And Effect Analysis (FMEA). Skripsi Universitas Muhammadiyah Surakarta. Surakarta. Universitas Muhammadiyah Surakarta.

Yuliana, O. Y. 2000. Penggunaan Teknologi Internet Dalam Bisnis. Retrieved from puslit2.petra.ac.id. http:/www.puslit2.petra.ac.id/gu dangpaper/files/1745.pdf 


\section{BIODATA PENELITI}

\section{Pipin Widyaningsih, S.Kom., M.Kom.}

Lahir di Boyolali pada tanggal 24 Januari 1984. Dosen Program Studi Sistem Informasi STMIK Duta Bangsa Surakarta. Saat ini mengampu mata kuliah algoritma dan struktur data, sistem basis data, pengembangan sistem informasi. Pengalaman penelitian dan pengabdian pada masyarakat antara lain Induksi Teknologi Marketing Digital Untuk Market Explanation di Kampung Batik Laweyan Surakarta. 